\title{
Innovative Activities of JSC 'Concern Rosenergoatom' to Ensure NPP Safety: Strategy and Plans to Implement Nuclear Knowledge Management
}

\author{
S.V. Eremin ${ }^{1}$, N.V. Tikhonov ${ }^{2, *}$, A.Yu. Yuzhakov ${ }^{2}$ \\ ${ }^{1}$ Department of Innovative Development, Concern Rosenergoatom, Russian Federation \\ ${ }^{2}$ All-Russian Research Institute for Nuclear Power Plants Operation, Russian Federation
}

Copyright $\bigcirc 2017$ by authors, all rights reserved. Authors agree that this article remains permanently open access under the terms of the Creative Commons Attribution License 4.0 International License

\begin{abstract}
The Russian operating organization Concern Rosenergoatom established a program for knowledge management $(\mathrm{KM})$ implementation in the organization, as part of ROSATOM State Corporation KM activities [1]. The plan includes activities both in the framework of classic knowledge management cycle: detection, preservation, retention, sharing and transfer, as well as creation of new knowledge such as training programs for new build nuclear power plants. The approach embraces key techniques overviewed in IAEA documents on KM and ROSATOM strategical focus on the commercial use of R\&D results and corporate knowledge and, thus, contributes to safe, reliable and efficient operation of NPPs.
\end{abstract}

Keywords Knowledge Management, Nuclear Power Plants, Innovative Development, Pilot Project, Commercial Application of Knowledge

\section{Introduction. General Information about JSC 'Concern Rosenergoatom' Performance Activities}

JSC 'Concern Rosenergoatom' (hereinafter Concern) is the operating utility and the leader of power generation division of State Corporation 'ROSATOM'. The share of Concern in power generation of Russian Federation reached $18.6 \%$ in 2015 , thus making it the largest power generation company in RF. The total established capacity of Concern is $27,127 \mathrm{GW}$ which is the second position among power generating companies in the world.

Concern operates the fleet of 35 reactors of different design at 10 nuclear power plants in Russia (18 -VVER reactors, 15- channel-type reactors RBMK, 2 -fast reactors with sodium coolant) [2]. Concern goal is to preserve the share and increase the total generated power on the basis of innovative projects.

In the nearest future the operation life of the power units with reactors VVER-440, VVER-1000, RBMK is planned to be extended after completion of full scale modernization of these units. Also several new power units with VVER-1000 and VVER-1200 reactors are under construction both in Russia and abroad. Thus the reactor fleet of Concern Rosenergoatom is constantly being renewed with new units being put in operation every year. In 2016 the new unit with BN-800 fast breeder reactor was put into commercial operation at Beloyarsk NPP. It provides for development of new elements of closed nuclear fuel cycle technology and confirms the leading position of Concern in fast breeder reactor design, construction and operation. In February 2017 a generation 3+ VVER-1200 Unit 6 was launched at Novovoronezh NPP. A floating NPP project is currently at the final stage of construction with startup scheduled to 2019.

All these activities are included into Concern innovative development strategy.

\section{Materials and Methods}

\subsection{Main Areas of 'Concern Rosenergoatom' Innovative Development}

Sustainable development of 'Concern Rosenergoatom' is based on innovations which are in-line with strategic goals of the State Corporation ROSATOM. These innovations include:

- Closed fuel cycle for NPPs;

- Development of decommissioning technology;

- Expansion of NPP projects based on Russian nuclear technologies worldwide;

- Management of NPP-related knowledge as a basis for innovative development. 
Completion of construction and successful start-up of BN-800 (Figure 1) unit significantly contribute to advance in closing nuclear fuel cycle. It is expected that the closed nuclear fuel cycle will be achieved through three main activities: modernization of existing reactor fleet, innovative recycling technologies for spent fuel processing and serial construction of BN-1200 fast reactor units, which detailed design was completed in 2016 [3].

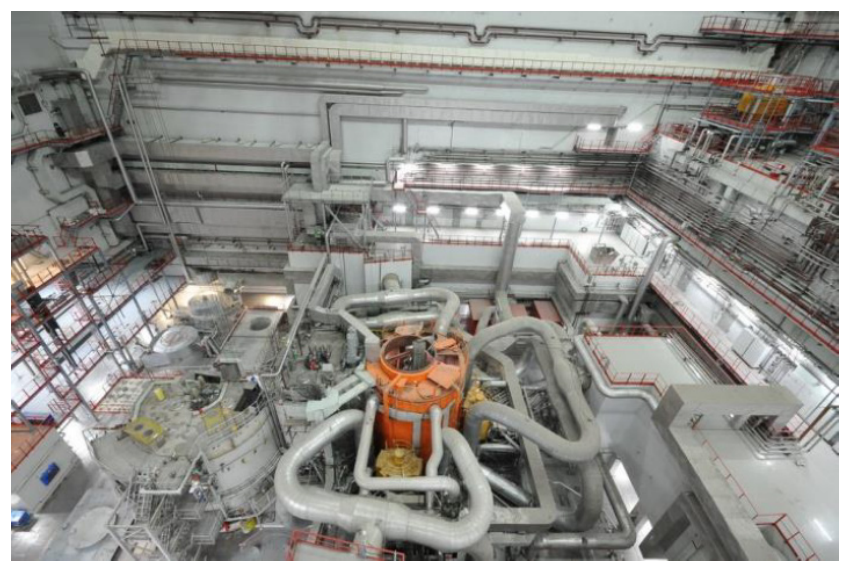

Figure 1. $\mathrm{BN}-800$ reactor view

In the coming years the technology for NPP decommissioning is going to be among the most demanded. The activities envisaged in this area include development of referenced decommissioning technologies, protect them with patents and registered know-how and promote worldwide, especially considering the ageing reactors of
Russian design in Eastern European countries which are approaching its life time termination.

Expansion to nuclear markets worldwide is in the focus of attention of ROSATOM. The total cost of negotiated ROSATOM contracts abroad has exceeded 100 billion US dollars(Figure 2).

The constantly growing presence at the world markets requires new innovative approaches to human resource development, protection of intellectual property for worldwide use and etc. These approaches are utilized in bilateral agreements on nuclear infrastructure development with countries of Bangladesh, Belarus, Bolivia, Egypt, Vietnam, as well as in personnel training, equipment supply, provision of maintenance services, repair and modernization of NPP units in many partner countries.

The above listed activities would not be successful without implementation of nuclear knowledge management concept which is a part of Concern innovative development program. The important tasks for KM in Concern include:

- Improving safe and reliable NPP operation and maintenance processes, extension of NPP life-cycle;

- Development of a set of innovative technologies including those for NPP decommissioning;

- Protecting intellectual property rights;

- Training of NPP personnel to be released from decommissioned units for new NPP design.

To solve these tasks a methodology of KM is implemented at ROSATOM [1].

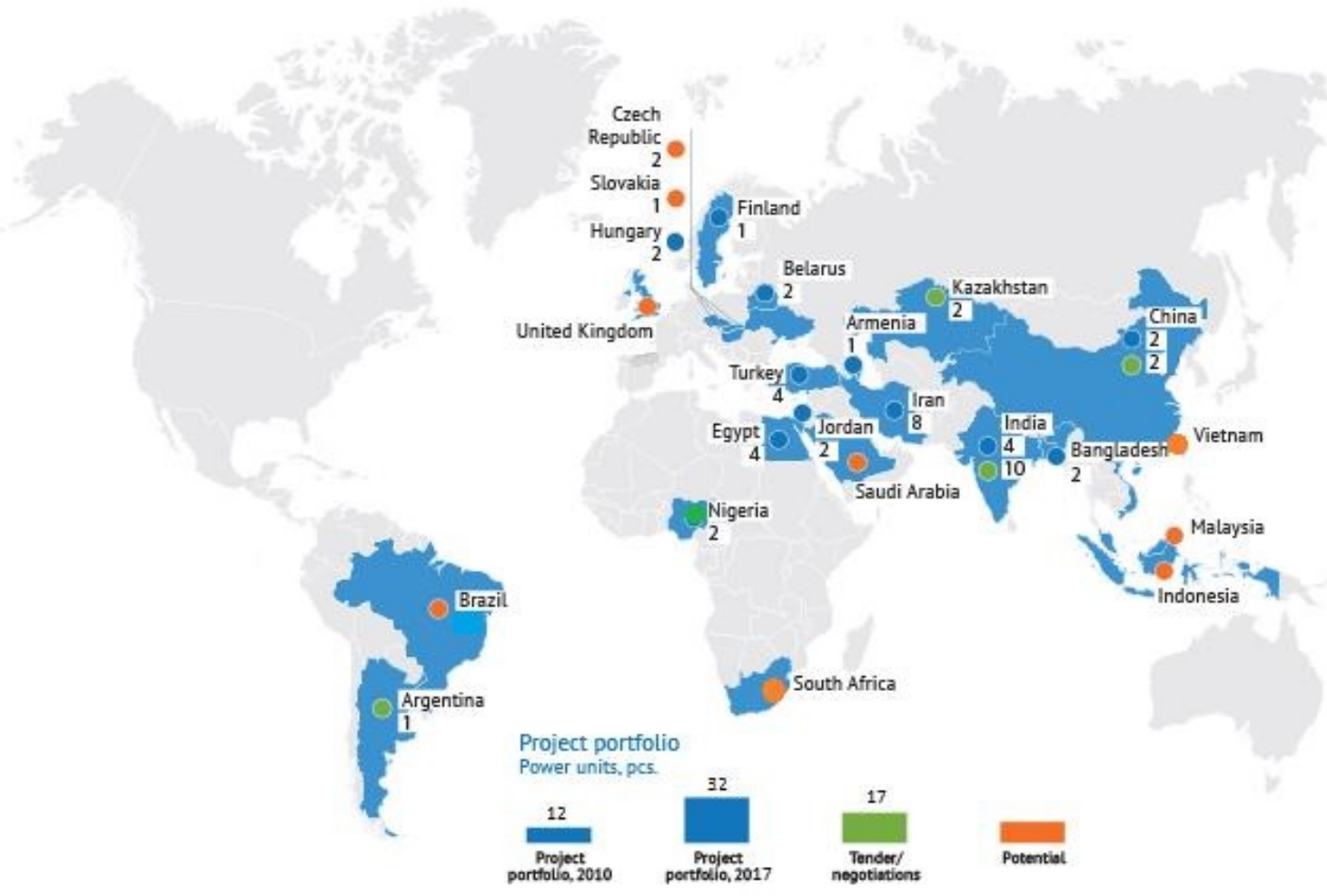

Figure 2. NPPs of Russian design to be constructed worldwide by ROSATOM group 


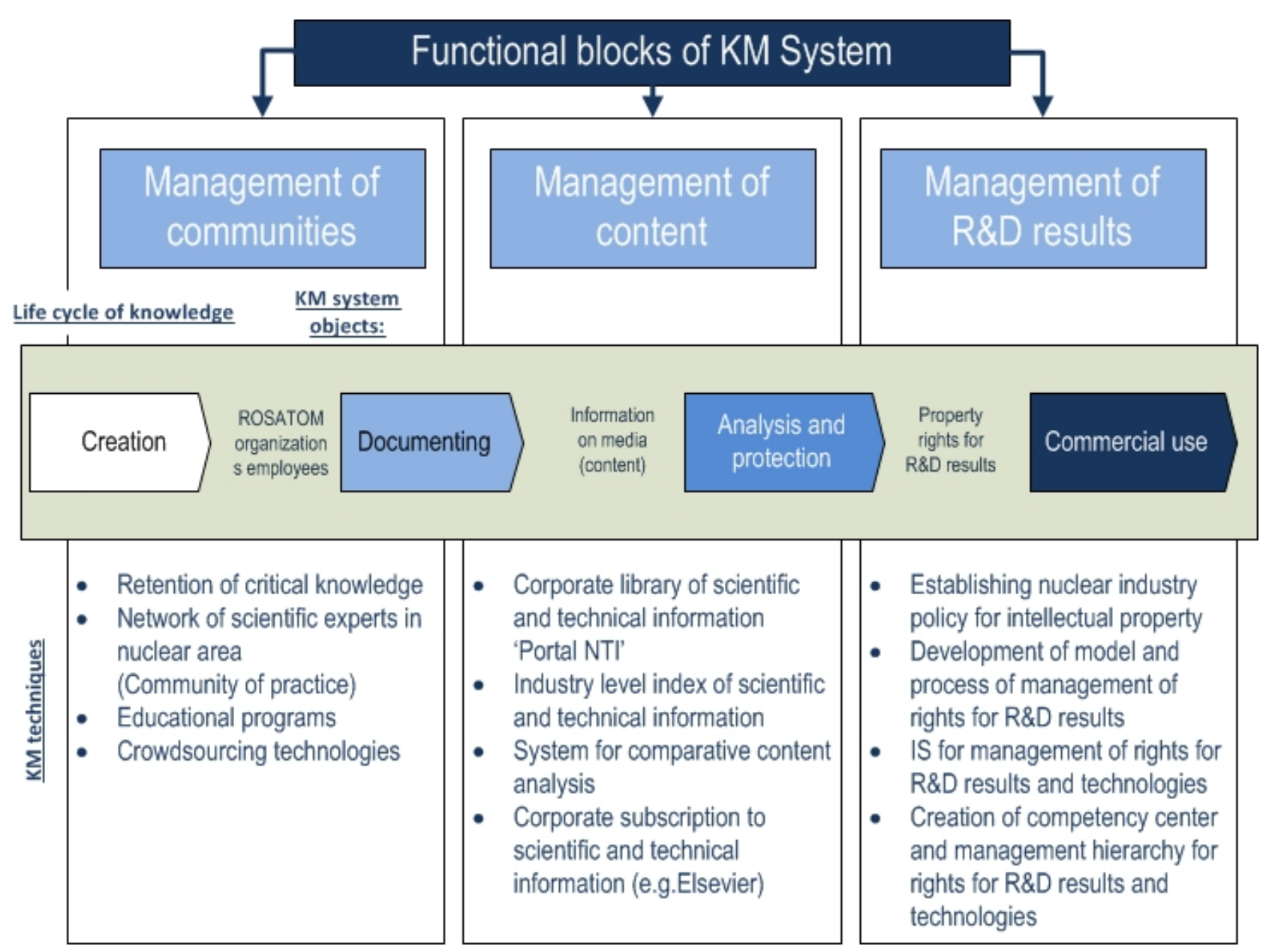

Figure 3. Functional blocks of NKM in State Corporation ROSATOM

\subsection{KM Methodology Applied in the State Corporation ROSATOM}

The key goal of KM implementation in ROSATOM State Corporation is to promote innovative technologies, reduce the overall duration of innovation lifecycle and assure growth of ROSATOM technologies' commercial applications [1]. To achieve these, four tasks are being performed:

- Continuing knowledge detection and capturing;

- Intensive knowledge sharing and circulation through effective cooperation of all internal and external users;

- Provision of data, information and knowledge to ROSATOM employees;

- Establishing of effective mechanisms for commercial knowledge usage.

The KM tasks are solved through the three functional blocks, namely:

- Management of scientific and engineering communities - focuses on development of competencies in R\&D, organization of professional communities, knowledge capturing and preservation;

- Management of scientific and technological content to increase effectiveness of all $R \& D$ activities through better access and usability of scientific and technological information;

- Management of rights for R\&D results and intellectual property focusing on the ROI increase (Figure 3).

In recent years the KM methodology applied resulted in the rapid increase of applications for state registration of $R \& D$ results in ROSATOM organizations and consequently in the double of total registered patents for innovative products owned by ROSATOM.

Concern introduced a program for $\mathrm{KM}$ in operating organization, which is the part of ROSATOM program. Action plan for the program includes activities within 'classic' KM cycle - knowledge caption, retention, documenting, preservation and transfer defined in ROSATOM Guidelines [4] as well as creation of new knowledge, e.g. personnel training programs for NPPs being under construction. The audit of company knowledge helps to determine what particular knowledge is the propriety of Concern, what knowledge is critical for safe and sustainable operation of generating company. Data, information and knowledge are generated at all stages of NPP life cycle from scientific research and development to decommissioning. The tasks of KM varies significantly through the life cycle stages and having a variety of unit designs for NPPs in 
operation one has to carefully plan and implement KM program at company level and downward to facilities level. The program aims to fully satisfy the operating organization needs and cope with challenges, matches the regulatory requirements and follows the IAEA recommendations.

The above described approach is the framework for all Concern Rosenergoatom initiatives in the field of nuclear knowledge management, including those described below.

\subsection{KM in the Field of OPEX Use}

The role of KM in the field of OPEX use for NPP construction and operation is marked by examples of important knowledge losses. The first one is the issue of capturing non-documented technical knowledge (in the form of 'technical decisions') applied at construction stage of NPPs (Figure 4). Implementing KM technology in this case results in

- Decreasing risks of loss of those knowledge obtained at construction stage;

- Return of documented knowledge into decision making process;

- Commercial use of captured knowledge in the field of NPP construction works.

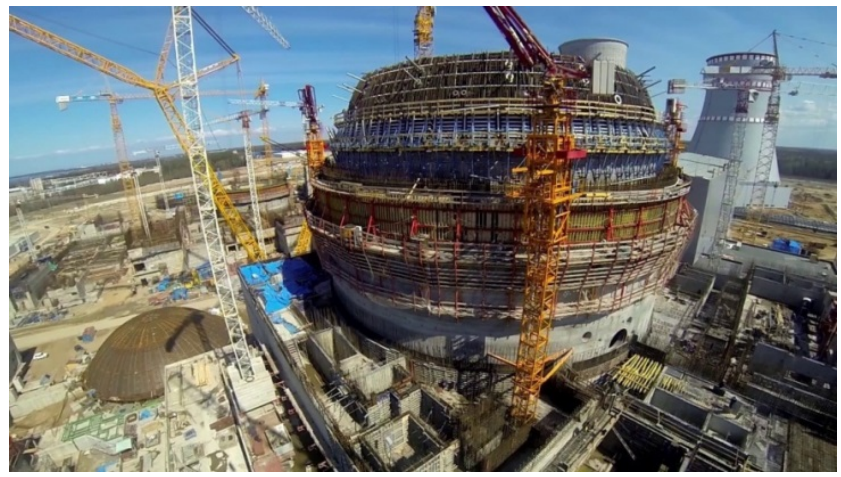

Figure 4. Leningrad NPP-2 construction stage

To determine the demand in non-completely documented technological knowledge capture the following activities are being conducted:

- Audit of critical knowledge to be captured in the field of NPP OPEX use (primarily non-completely documented 'technical decisions'), reveal of tacit knowledge in this area;

- Risk assessment of critical knowledge loss (related to OPEX use);

- Taxonomy of knowledge related to NPPs with different technology (RBMK, VVER, BN);

- Critical knowledge retention and documenting;

- Setting a process and development of procedures to support this process on a permanent basis.

The revealed knowledge in OPEX area documented into guidelines, technical reports and training materials and is available to employees via corporate portal brought back into company operation practice.

\subsection{Knowledge Management in Decommissioning}

More than a half of Rosenergoatom reactor fleet are either close to its design life time or have exceeded it. The total market capacity of NPP decommissioning services is estimated to 300 billion dollars by $2030[5,6]$. In this regard, $\mathrm{KM}$ application in decommissioning requires proactive and systemic approach, primarily at the preparatory stage. The set of activities as described in previous section has been initiated. The use of a state-of-art information technology (Multi-D) provides a unified solution to support NPP decommissioning activities (Figure 5).

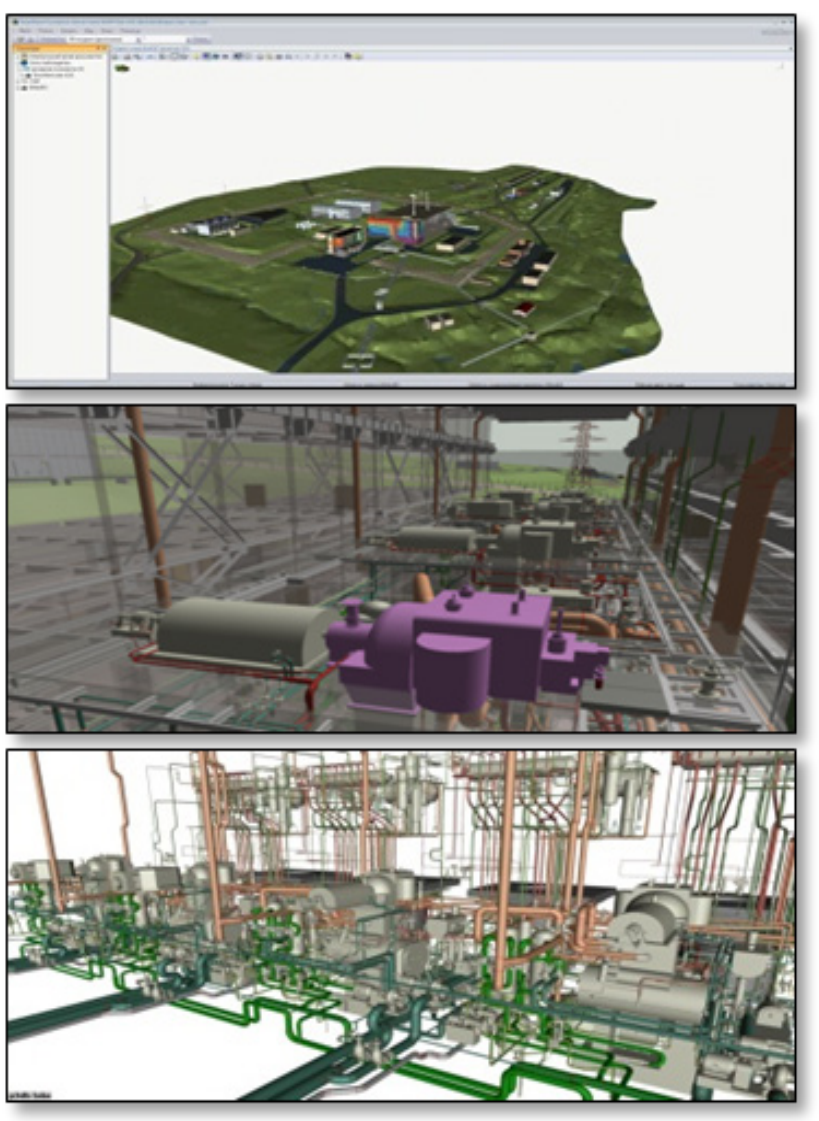

Figure 5. NPP digital model in Multi-D technology for decommissioning of Bilibino NPP

For many years, Russian Research Institute for Nuclear Power Plants operation (JSC VNIIAES) has been accumulating knowledge on NPP decommissioning in databases, guides and project documentation. The scheduled activities include development of training materials and conduct training for decommissioning personnel with the use of preserved knowledge in this field as well as elaboration of detailed documentation for NPP decommissioning process.

\subsection{Knowledge Management Projects at 'Concern Rosenergoatom'}

Russian operating organization Concern Rosenergoatom faces the well-known challenges in nuclear industry [7]: 
ageing of NPPs personnel and low turnover, which prevents from knowledge transfer between experienced and young employees and thus lead to increased number human performance errors. There are also a constant demands for increases productivity, decreases risks of NPP construction and operation phases, proactive use of OPEX, and the need in qualified human resources for newly built plants. To response these challenges and achieve excellently in plant performance a program for KM implementation was initiated which includes activities both at the company and utility levels.

\subsection{Case: Implementation of Knowledge Management at Smolensk NPP}

Smolensk NPP initiated the program for KM implementation in 2011. The initial project for knowledge management and retention at Smolensk NPP included identifying and capturing the critical knowledge in two staff groups:

- Control room personnel who demonstrates error free performance; and

- $\quad$ Recognized experts at the NPP prior to retirement or permanent leave.

The introduction to KM was performed with the assistance of JSC VNIIAES, which is responsible for engineering support services for NPPs in operation in Russia. International level experts and the IAEA supported the a.m. benchmarking process.

Identification of experts was performed in three domains:

- Control room personnel (Figure 6) with an error free performance (also considering crew make-ups);

- Questionnaires obtained from main NPP departments; and

- $\quad$ Staff appraisal by the head of department.

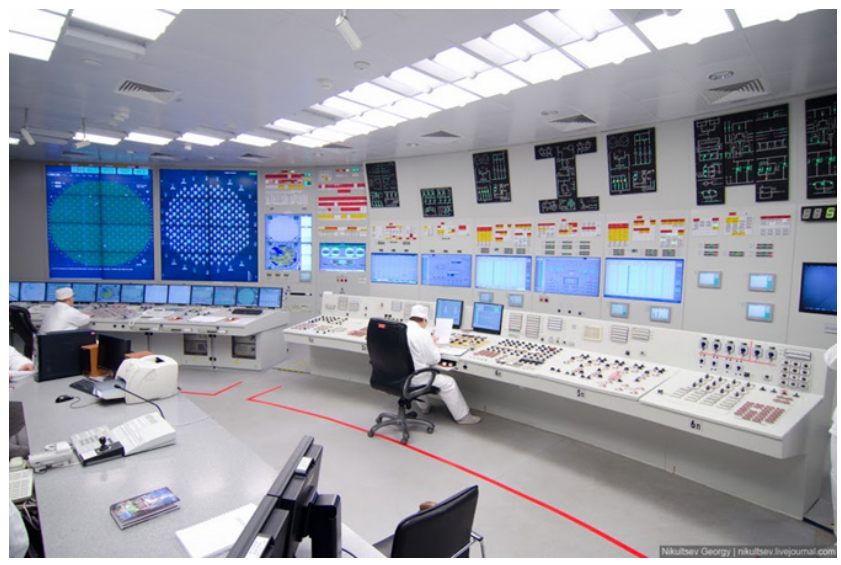

Figure 6. Control room of Smolensk NPP Unit 3

Each NPP deputy chief engineer identified experts in their division and ranked them based on an importance of knowledge and time to be an expert in the domain.

Further, interviews were conducted with the identified experts (knowledge elicitation step) in order to:
- Identify an expert on behaviors associated with error free operation in a control room environment;

- Identify an individual that can interview the operators on their behaviors used to achieve error-free control room performance;

- Identify the job positions at risk of knowledge loss.

All these activities were carried out together with the development of KM process model, supported by model description and procedure for knowledge detection, capture, retention and transfer at Smolensk NPP.

The key results of the pilot project include identified key job positions, skills and competencies at risk of knowledge loss, plan for knowledge capture and retention, documented knowledge and inputs to changes in training materials and programs, the revised plan for personnel for personnel promotion and staff replacement. All methods, procedures and recommendations received at Smolensk NPP are applicable for other utilities and have been included into the ongoing KM project to be disseminated at the operation organization level within the fleet.

\subsection{Knowledge Management and Improvement of Personnel Training}

Concern Rosenergoatom continuously develops and improves its personnel thus achieving safe and reliable operation of nuclear power plants. KM process contributes recently to the following improvements:

- A system to retain critical knowledge was implemented;

- A bank of training materials in electronic formats was established;

- A technique to transfer new knowledge to personnel through initial and continuous training programs was developed.

These improvements contributed to the following activities:

- Revision of training materials, initial and continuous training programs was performed;

- The list of normative documents, training materials and training programs for future development was defined;

- The database of training programs was elaborated for which competency development and training is conducted at external educational organizations;

- $\quad \mathrm{KM}$ process through regular monitoring of risks for critical knowledge losses also contributed to timely planning of staff replacement for job positions required personal licenses to conduct operation.

The up-to-date training tools are used in the personnel training including full-scope simulators capable to model the complete range of normal operation modes and emergency regimes (Figure 7,8).

The project to establish a system to retain critical knowledge is ongoing. The objectives of this project are:

- Decrease the risk of critical knowledge losses due to personnel leaving their positions; 
- Assure knowledge transfer through different generations of employees;

- Incorporate critical knowledge into organization activities;

- $\quad$ Assure commercial application of critical knowledge.

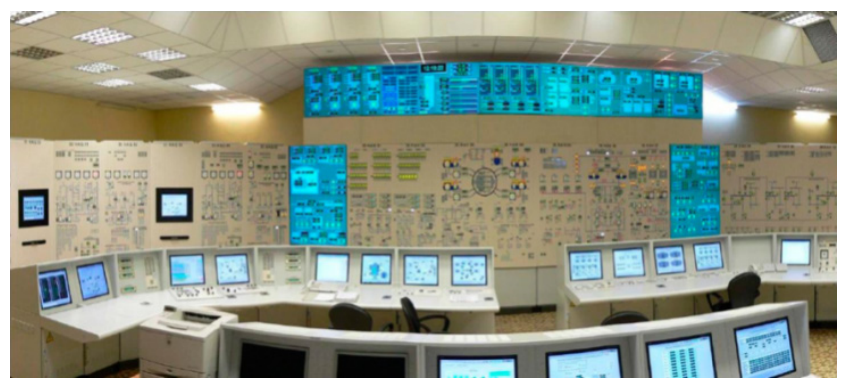

Figure 7. Full-scope simulator of Kalinin NPP Unit 3 (vendor - Russian Technical Support Organization "VNIIAES," JSC)

One of challenging examples in $\mathrm{KM}$ is management of knowledge and competencies of employees at the sites with different reactor technology in use (e.g. RBMK reactors in operation and VVER reactors under construction at Leningrad NPP site).

The following methods are applied in order to achieve said objectives:

- Audits of knowledge;

- Knowledge mapping;

- Risk analysis of critical knowledge loss;

- Review and development of training programs and training materials for NPP job positions;

- Documenting results of intellectual activities to be registered for further use on the commercial basis.

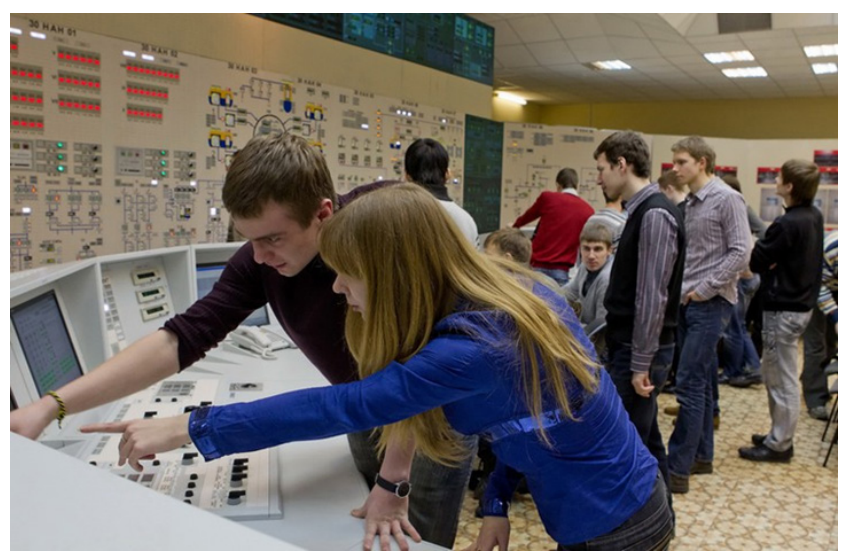

Figure 8. A lesson for students at full-scope simulator of Kalinin NPP Unit 4

The objective of the project to establish the bank of training materials in electronic formats is to ensure access and availability of training materials for all employees and, thus, improve the quality of training. This is achieved by:

- $\quad$ Retaining of training materials existing at all NPPs of Rosenergoatom;

- $\quad$ Producing digital copies of retained paper materials;

- $\quad$ Systematizing of materials into hierarchical catalogue;
- Publishing training materials on corporate intranet resources.

One of the examples of commercial use of knowledge is the set of training programs and training materials developed by Concern Rosenergoatom for personnel of those NPPs which are being constructed abroad on the basis of VVER technology. Necessary licenses to conduct training for these programs were obtained.

\section{Conclusions}

Innovative development of a nuclear power plant fleet in Russian Federation creates a constant need for effective management of the full scope of nuclear knowledge, making the existed and newly created knowledge available to others both efficiently and effectively. To achieve this Rosenergoatom has launched a long-term program to establish a corporate knowledge management process as part of its management system processes, and initiated several projects in KM both at corporate and NPP levels. The initiated projects are important tools for implementing knowledge management strategy in Concern Rosenergoatom. They embrace all the key technique described in the IAEA related documents [7-9]. The results achieved in these projects can be applied to other facilities and activities.

\section{Acknowledgements}

The authors are grateful to experts for their appropriate and constructive critiques and suggestions to improve this paper.

\section{REFERENCES}

[1] The Program for Establishing Knowledge Management System of State Corporation ROSATOM and its organizations for 2012-2015 - ROSATOM, Moscow, 2012

[2] Annual Report 2016 of Concern Rosenergoatom, http://www.rosenergoatom.ru/about

[3] Vasiliev B. Perspectives of nuclear power with fast sodium cooled reactors. Journal of Rosenergoatom \#1 2017, pp.42-45

[4] Guidelines for Critical Knowledge Retention in ROSATOM Organizations - ROSATOM, Moscow, 2013

[5] Chepaikin I.A. An assessment of world NPP decommissioning market size by 2030, MEPhI, 12.12.2015

[6] IAEA Report on Decommissioning and Remediation after a Nuclear Accident, International Atomic Energy Agency, 2013 available from $\mathrm{http}: / / \mathrm{www}$.iaea.org

[7] STI/PUB/1248 Risk Management of Knowledge Loss in Nuclear Organization - IAEA, Vienna, 2012 
[8] IAEA-TECDOC-1675 Knowledge Management for Nuclear Research and Development Organizations - IAEA, Vienna, 2012
[9] IAEA-TECDOC-1510 Knowledge Management for Nuclear Industry Operating Organizations - IAEA, Vienna, 2012 